\title{
Doutrina da ciência e arte de viver
}

\section{Federico Ferraguto}

\section{(2) OpenEdition}

\section{Journals}

Edição electrónica

URL: http://journals.openedition.org/ref/647

DOI: $10.4000 /$ ref.647

ISSN: 2258-014X

\section{Editora}

EuroPhilosophie Editions

Refêrencia eletrónica

Federico Ferraguto, « Doutrina da ciência e arte de viver », Revista de Estud(i)os sobre Fichte [Online] 11 | 2016, posto online no dia 01 junho 2016, consultado o 10 dezembro 2020. URL : http:// journals.openedition.org/ref/647 ; DOI : https://doi.org/10.4000/ref.647

Este documento foi criado de forma automática no dia 10 dezembro 2020

(c) EuroPhilosophie 


\title{
Doutrina da ciência e arte de viver
}

\author{
Federico Ferraguto
}

\section{Uma filosofia para a vida}

1 A ideia global da doutrina da ciência é definida pela tensão entre filosofia e vida. Em seu momento inicial, o exercício da doutrina da ciência consiste em elevar-se da consciência ordinária até o ponto de vista filosófico, Fichte descreve a necessidade e a modalidade desta elevação nas aulas introdutórias na doutrina da ciência. Após o desdobramento da doutrina da ciência como disciplina filosófica específica (doutrina da ciência in specie) e das ciências filosóficas particulares, que podem ser deduzidas a partir dela (doutrina do direito, da moral, da natureza e estética), a doutrina da ciência tem de se voltar para a vida, através de sua aplicação nela. A aplicação visa à dissolução da filosofia na sabedoria ou da atividade do filosofar numa práxis que vive a própria filosofia, após ter esgotado seu caminho argumentativo e reflexivo ${ }^{1}$.

2 No contexto sistemático fichteano, a aplicação da filosofia na vida não corresponde a um conceito geral ou abstrato, mas envolve a constituição de disciplinas filosóficas específicas que não refletem os padrões de uma filosofia como ciência rigorosa, mas constituem uma "prática" do ponto de vista da doutrina da ciência. Elas são disciplinas como a política, a ascética, a pedagogia, e a pastoral. Nas aulas sobre a Aschetik als Anhang zur Moral, de 1798, o documento talvez mais detalhado sobre o problema da função das ciências filosóficas aplicadas ${ }^{2}$, Fichte esclarece que a aplicação teria de recompor a separação entre teoria e práxis, ou seja, a entre a compreensão teórica da liberdade como princípio constituinte do mundo e o seu uso pelo ser humano concreto. Mais especificamente, a filosofia aplicada seria uma ciência intermediária, cuja tarefa é a determinação dos presupostos pela "realização em situações empíricas determinadas das pretensões da razão"'.

3 A dinâmica geral de sobreposição e de reviravolta da filosofia na vida visa à formação de um homem novo, de um mundo novo, de uma re-criação e de uma reforma de todo o gênero humano. Esta reforma pode acontecer somente sob a guia de um "sábio" que não impõe preceitos, mas indica o percurso que o indivíduo tem de acompanhar 
autonomamente para chegar numa a uma vida pura racional, até expondo as implicações políticas e sociais dessa vida ${ }^{4}$.

4 O novo mundo e o homem novo a que se refere a doutrina da ciência não exprimem, porém, uma ordem radicalmente diferente da vida ordinária ou alternativa a ela. $\mathrm{Na}$ verdade, a filosofia aplicada não pode recompor toda a separação entre teoria e práxis e nunca poderia compenetrar-se filosoficamente de uma realidade dada. 0 trabalho dela é bem mais precário e provisório: "na medida em que o hiato permanece, é preciso recorrer ao sentido comum e tem de ser formado artificialmente, pela ciência teórica [ou seja, a doutrina da ciência, F.F.] e pela ciência intermediária [ou seja, a filosofia aplicada]"5. Esta formação do mundo novo e do homem novo representam, então, o resultado de um trabalho desenvolvido dentro dos limites da vida ordinária, que visa uma mudança conforme a razão. Essa mudança acontece com referência a uma ideia ou a um modelo ideal (Fichte fala de Gesicht), elaborada por meio de uma compreensão da estrutura geral da razão e por meio de um processo de autocompreensão por parte sujeito filosofante. É através deste sujeito que a razão se auto-configura como operatividade, ou seja como força efetiva ${ }^{6}$.

De acordo com o que Fichte sustenta nas aulas introdutórias da doutrina da ciência ministradas entre 1810 e 1813, o homem novo criado pela doutrina da ciência tem de renunciar a si mesmo e se fundir com a unidade da razão, entendida como a raiz íntima de seu agir e pensar. Por outro lado, essa renúncia pode acontecer apenas como consequência de todo desdobramento de sua racionalidade, por meio de práticas, exercícios, tentativas e experimentos mentais e linguísticos sobre si mesmo que permitem um crescimento das próprias capacidades cognitivas e conativas na cena constituída pela própria doutrina da ciência. Quem faz uma filosofia transcendental assume certa postura e possui certo estilo: ou seja, vincula as possibilidades de sua existência a um horizonte específico, sobrepõe ao próprio arbítrio uma necessidade superior, fazendo deste uma prática eficaz de liberdade, por meio de uma aquisição gradual de competências e habilidades ${ }^{7}$.

Deste ponto de vista, a doutrina da ciência poderia ser assimilada a uma "arte de viver", ou seja, à definição de um processo pelo qual o ser humano torna-se consciente de si mesmo por meio de uma atividade reflexiva intencional e artificial e, a partir desta consciência de si mesmo, doa um sentido a sua vida: estiliza a sua existência individual e social com referência a um horizonte de possibilidade que, incialmente virtual, tornase presencial numa ação concreta ${ }^{8}$.

7 A possibilidade da doutrina da ciência de Fichte ser esclarecida à luz do conceito de arte de viver torna-se interessante pelo menos por duas razões. A primeira é histórica e pertence à ideia fichteana de acordo com a qual a filosofia (e em especial) a doutrina da ciência não deveria permanecer uma ciência teórica abstrata e sim incidir na mudança progressivamente racional das condições existenciais (i.e. sociais, individuais, políticas e éticas) do próprio ser humano. O segundo seria de natureza teórica, pois na discussão filosófica contemporânea foram apresentados modelos de compreensão filosófica da realidade que enfatizaram a ideia de filosofia como "arte de viver". Esta expressão não tem de ser entendida no sentido de uma estetização da existência pessoal ${ }^{9}$, mas no sentido de uma filosofia como prática e como exercício individual que permite adquirir competências e posturas capazes de formar a vida individual na forma de uma aproximação para com um ideal dotado de valor, tal como levado à luz por Michel Foucault ${ }^{10}$. 
8 Neste artigo, portanto, procurarei esclarecer os limites nos quais se torna possível compreender a doutrina da ciência à luz das concepções contemporâneas da arte de viver e irei tentar unir duas linhas de investigação. A primeira é teórica e textual, relativa à concepção de ascética que Fichte apresenta nas aulas de 1798 sobre a Aschetik als Anhang zur moral, relativamente negligenciadas pela Fichte-Forschung (\$§ 2-3), e a interpretação fichteana do homem prudente (besonnen) apresentada como comentário ao capítulo XXV do Príncipe, de Maquiavel, que constitui um trecho fundamental do ensaio Mchiavelli als Schriftsteller, de 1807 (§ 4). A segunda linha de investigação seria mais histórica. Ela, de fato, põe em questão a possibilidade de aproximar a ideia fichteana de ascética à reflexão contemporânea sobre a filosofia da arte de viver, aberta por Michel Foucault e, numa época mais recente, desenvolvida sistematicamente por Wilhelm Schmid ${ }^{11}(\S \S 4-5)$.

\section{Esquecer o sentido da razão}

9 Aplicada à doutrina da ciência de Fichte, a expressão "arte de viver" pode ser entendida, de maneira geral, como uma filosofia atenta à existência concreta, bem diferente de um idealismo especulativo, ou ético, baseado em um princípio moral absoluto que não tem relação nenhuma com a vida particular do indivíduo ${ }^{12}$.

Num sentido mais específico, uma assimilação da doutrina da ciência à arte de viver implica um confronto com uma tradição filosófica nascida na idade clássica que, atravessando a época moderna, se encontra também na discussão filosófica contemporânea, em particular, nas reflexões de Foucault, Hadot, Krämer ou Wilhelm Schmid, o qual, por sua vez, tentando ampliar e atualizar o projeto foucaultiano, sintetiza estas posições de maneira diferente ${ }^{13}$.

11 No caso de Foucault, a ideia de arte de viver visa a uma genealogia das relações políticas que definem a sociedade moderna, a partir do processo através do qual o indivíduo constitui-se a si mesmo como substância ética ${ }^{14}$, na gestão das suas relações com o prazer físico e, mais especificamente, com o prazer sexual ${ }^{15}$. Por outro lado, a ideia foucaultiana é istrumento para a formação de uma ética capaz de responder aos problemas dos movimentos do fim dos anos ' $70^{16}$. A concepção foucaultiana da arte de viver nasce da admissão de que cada ação moral implica uma relação com a realidade na qual é realizada e com o código ao qual se refere. "Mas é verdade também que ela implica certa relação consigo mesmo". Esta relação não corresponde, de acordo com Foucault, a uma consciência imediata de si mesmo, mas a uma dinâmica na qual o indivíduo constitui a si mesmo como sujeito moral, "circunscreve a parte de si mesmo que constitui o objeto desta prática moral" e "visa a certa maneira de ser que coincide com a realização moral de si mesmo [...], age sobre si mesmo, começa a se conhecer, controla a si mesmo, se experimenta, se aperfeiçoa, se transforma" ${ }^{17}$.

12 A ideia de "cuidado de si", assim como a de "ascética" ou a da possibilidade de conceber "técnicas de existência" -típicas do projeto foucaultiano - são, ademais, aprofundadas de maneira mais construtiva do que expositiva, por Wilhelm Schmid, que tenta ampliar a concepção de Foucault em relação à ligação entre sexo, moral e poder. Schmid tenta privilegiar o aspecto "quase transcendental" da arte de viver, que visa "sustentar o indivíduo no processo através do qual ele chega a adquirir uma capacidade autônoma de juízo, na efetuação de uma escolha e na ação implicada por ela". Por meio da reflexão filosófica, de fato, "o indivíduo se torna capaz de compreender melhor a 
maneira em que vive e, de vez em quando, de intervir para mudá-la, na medida em que ela providencia um inteiro leque de possibilidades de compreender e de agir" ${ }^{18}$.

Para além da primeira impressão, o conceito de arte de viver que amadurece neste contexto não coincide com uma vulgarização da filosofia, como se fosse espécie de autoajuda, nem com a tentativa de sublimação da existência concreta rumo a uma vida filosófica. A arte de viver esclarece as modalidades de uma conduta reflexiva individual, com respeito à qual o exercício da filosofia é introdução, preparação e exortação ${ }^{19}$. A arte de viver não é prescritiva nem consiste numa iniciação à vida boa. Analisa $\mathrm{e}$ descompõe tudo o que aparece como significativo para conduzir a uma existência concreta, abre possibilidades existenciais, propõe-se a encontrar as condições de possibilidade da ferramenta oferecida pela existência cotidiana e apresenta uma metodologia que permite ao indivíduo compreender sua existência efetuando suas escolhas no horizonte de uma coerência racional. Trata-se de uma tarefa muito próxima daquela que Fichte atribui à sua "ascética" como disciplina filosófica aplicada. Sendo impossível como ciência rigorosa, a ascética tem a função de manter o homem firme na decisão fundamental que define a sua existência individual, por meio da vinculação da liberdade da sua vontade ao princípio de acordo com o qual cada ação concreta tem de expressar uma racionalidade plena; ou seja, completamente justificável e universal ${ }^{20}$.

14 Nesse nível fica clara a necessidade de integrar antropologia e ética, isto é, a compreensão da ética em relação à possibilidade de que o ser humano, como "ser que age de modo livre, que faz, pode fazer ou deve fazer de si mesmo", forme autonomamente a sua existência ${ }^{21}$. Para realizar esta integração, que já foi sublinhada por Kant na Antropologia pragmática e justamente valorizada por W. Schmid ${ }^{22}$, não é importante somente a capacidade autorreflexiva do ser humano, mas também o desenvolvimento da sensibilidade, o que igualmente representa o coração da antropologia kantiana. Nessa obra, Kant propõe, para refinar a sensibilidade, algumas técnicas (como contraposição, renovação, intercâmbio, crescimento da intensidade das impressões sensíveis) e integra, nesse mesmo plano, o sonho e a imaginação; além disso, abre espaço para a questão acerca da relação entre o prazer e a dominação do espírito diante das paixões ${ }^{23}$.

Do mesmo modo, Fichte, nas aulas sobre a Aschetik als Anhang zur Moral ${ }^{24}$, desenvolve este modelo, sublinhando os aspectos heurísticos envolvidos na formulação de uma ascética, os quais definem também o lugar sistemático dela ${ }^{25}$. A priori, de fato, a ascética é impossível, ou melhor, banal. Baseia-se em um pressuposto já esclarecido na ciência ética: o ser racional nunca poderia agir contra a razão, ou seja, de forma má ${ }^{26}$. Uma ação desse tipo seria propriamente de um ser irracional, o que na linguagem ordinária seria chamado de "diabo" 27 . Retomando uma estrutura conceitual já empregada no Ensaio sobre uma crítica de toda revelação ${ }^{28}$, Fichte esclarece, porém, que a ascética faz sentido, pois o indivíduo concreto é constituído não apenas pela razão, mas também pela sensibilidade e, por isso, sempre pode, desviado pela sensibilidade, esquecer qual é o sentido de sua decisão fundamental, e, logo, pode "perder, por causa de seus impulsos sensíveis, seu caráter" 29 . Então, continua Fichte: "O homem que quer cumprir seriamente o próprio dever e conhece este perigo por meio do saber ou por experiências passadas põe-se necessariamente a tarefa de remediar; e esta tarefa é a mesma da ascética, da qual estamos falando" ${ }^{30}$. Como descrição dos pressupostos para cumprir essa tarefa, a ascética oferece um panorama sobre os instrumentos úteis para 
manter presente o pensamento de nosso dever e, na medida em que é coerente com a estrutura da sensibilidade humana, a ascética irá consistir na busca pelos "meios mecanicamente eficazes pelos quais deve vir à luz um conceito determinado de acordo com uma regra interior" ${ }^{31}$. Estes meios, de acordo com Fichte, existem e têm de ser encontrados mediante um exercício - ou uma prática - sobre si mesmo ${ }^{32}$.

\section{Exercício}

Vê-se, deste modo, que, em Fichte, a ascética tem de ser entendida no sentido clássico desta palavra, como dominação controlada e gradual sobre si mesmo ${ }^{33}$. Num sentido mais estrito, ascética (áskēsis, em grego; exercitium em latim) indica o exercício físico, psicológico e espiritual, por meio do qual o indivíduo pode formar e trans-formar sua vida. De um ponto de vista transcendental, é correto dizer que a ascética consiste no percurso de formação de um si que já é sujeito e objeto de si mesmo. É sujeito, porque é quem exercita uma atividade formativa; é objeto, uma vez que representa o termo de referência de sua própria atividade formativa. Na base deste processo se dá uma dinâmica de progressivo estranhamento ou alienação de si mesmo. 0 eu tem de sair de si mesmo, referir-se ao outro de si, projetar uma condição futura antecipada pela imaginação e executá-la, embora com alguns limites, por meio de sua ação ${ }^{34}$.

O exercício e a prática ligados a essa dinâmica não têm função produtiva, mas heurística. Não produzem algo novo, mas permitem trazer à luz e levar a consciência à raiz autêntica de si mesma. Isso se dá também nas suas expressões clássicas, consideradas por Foucault, o momento fundamental no qual o sujeito se constitui a si mesmo como ser moral; a ascética, para Foucault, "não é organizada nem pensada como um conjunto de práticas específicas, no sentido de uma arte da alma". De um lado, não se pode distinguir o exercício para alcançar a virtude da própria prática da virtude. De outro lado, o desenvolvimento da ascética, na medida em que não corresponde a uma ciência específica, pode emprestar suas práticas para outros âmbitos da sabedoria. Mais especificamente, o trabalho sobre si mesmo reflete o trabalho sobre os outros. Na concepção fichteana, também, a ascética, entendida como educação da sensibilidade humana e típica da pedagogia, torna-se educação de si mesmo e necessária estimulação da lembrança, da imaginação e da atenção $0^{35}$.

18 A ascética fichteana parte da seguinte hipótese: que haja um momento no qual a determinação da razão, destacada por uma ação conforme a lei moral, seja captada pela imaginação, como num sonho, e o sentido racional do agir seja, assim, esquecido e expropriado de sua convicção ${ }^{36}$. A imaginação desempenha o papel moldar o comando da lei moral até fornecer um modelo de ação concreta e, neste sentido, de torná-lo disponível ao agir individual, como horizonte específico de sua possibilidade. Porém, como a caraterística da imaginação é também a de oscilar entre posições e opções diferentes, no nível da imaginação a disposição à razão poderia permanecer sempre perdida, o que favoreceria o impulso natural ${ }^{37}$. 0 objetivo da ascética é, então, o de reforçar a lembrança da disposição à racionalidade por meio do mecanismo de associação de ideias.

É por meio da associação de ideias que se torna possível ligar antecipadamente "a representação dever à representação de suas ações futuras". Fichte esclarece este ponto afirmando que, pela associação de ideias, "o conceito 'eu preciso agir' e o 'eu preciso agir em conformidade com o dever' deveriam ser unificados inseparavelmente, tal 
como podem sê-lo dois conceitos"38. Ademais, na medida em que a associação de ideias não é processo mecânico, mas, pelo menos no seu momento inicial, é dependente do arbítrio do sujeito, o próprio arbítrio tem de ser estimulado através de exemplos e exercícios efetuados pelo indivíduo particular ${ }^{39}$. 0 conjunto dessas tentativas expõe o processo gradual da constituição do sujeito como ser moral, o que faz sentido apenas no âmbito empírico. A possibilidade de associar a representação da razão à do agir futuro de um indivíduo é condicionada pela distância que este toma de si mesmo, o que, para Fichte, coincide com um autoexame (Selbstprüfung), ou seja, com uma reflexão geral sobre si mesmo e sobre as motivações do próprio agir pessoal. A Selbstprüfung representa a regra primeira e fundamental da ascética, esta faz com que o indivíduo delibere sobre a determinação de suas ações e veja o risco desta acontecer sem ser conforme à representação do dever ${ }^{40}$. De um ponto de vista antropológico, esta tomada de distância se torna possível na medida em que a sensibilidade constitui somente uma tendência do ser humano, deixando-o livre para acompanha-la ou não: "o homem, como tal, não recebe da natureza nem inclinações nem afeições nem paixões. Ele depende exclusivamente da liberdade" ${ }^{41}$. A associação de ideias esclarece e traduz em ação este tema transcendental e torna possível a conformidade do conjunto das representações sensíveis com alguma determinação possível da liberdade. A Selbstprüfung - segunda regra - corresponde, então, a uma orientação da atenção sobre si mesmo e, portanto, a uma determinação concreta da vontade. Deste modo, o indivíduo pode não apenas compreender a si mesmo como um ser projetual, mas também abrir o leque de alternativas que ele pode estabelecer na conexão entre a representação de suas ações futuras e a representação de suas ações derivadas das percepções sensíveis ${ }^{42}$. A terceira e última regra da ascética fichteana pertence ao que é produzido na associação das ideias, algo que não tem de ser apresentado como resultado de uma ação mecânica: "O esquecimento das melhores intenções fica sempre possível [...] por isso é preciso de um autoexame repetido da bondade dos princípios de cada ação. Constata-se o contrário ( a saber, os princípios não são bons. Nota do editor), então se tem que achar uma nova regra de comportamento"43.

O conjunto dessas regras, que, de acordo com Fichte, formam uma arte que cada um deve aplicar na sua vida, tem de refletir o princípio fundamental da ascética: "Não se abandonar à condição sensível, vigiar a si mesmo e acostumar-se a ser dono consciente de si mesmo. Esta atenção ininterrupta sobre si mesmo é observação de si, ato de reflexão permanente, não para aprender, mas para assumir alguma postura (Halten). A regra fundamental da ascética é, então: observa continuamente a ti mesmo, mas com liberdade cuidadosa" ${ }^{44}$.

21 Atenção e autoreflexão representam, nesse sentido, a base para exercitar uma vigilância sobre si mesmo, a qual, para retomar uma formulação foucaultiana, é serial e, ao mesmo tempo, circunstancial ${ }^{45}$. Serial, pois a ascética não fornece nenhum padrão universal para julgar as ações particulares, mas examina a cada vez a conexão entre, de um lado, ações particulares e, de outro, a relação da ação estimulada pela sensibilidade com uma representação geral do dever, ou seja, da razão. Circunstancial, porque o autoexame permite revisar a cada vez o que é produzido pela associação das ideias, criando regras específicas diversas, que têm uma validade contextual e individual. Todo este processo tem a função de produzir uma apropriação de si mesmo (sophrosyne) ou de exercer um controle sobre si mesmo. Fichte o denomina Besonnenheit, que, para empregar um conceito típico da arte de viver, coincide com certo "estilo". 


\section{Estilo e habilidade} elevação ou introdução na doutrina da ciência. Esta prática, na verdade, desenvolve-se através de exercícios e de tentativas que pressupõem e, ao mesmo tempo, têm por objetivo, a constituição de um ser humano coerente de um ponto de vista ético e moral ${ }^{49}$, o que sempre se dá através de uma estimulação específica das faculdades sensíveis do ser humano ${ }^{50}$. Do ponto de vista existencial, pelo contrário, idêntica dinâmica é apresentada por uma definição pragmática da Besonnenheit, que parece antecipar o tratamento do mesmo conceito que está presente na XIII lição da Logica transcendental ${ }^{51}$, no ensaio sobre Maquiavel: "Quem é estimulado de verdade a fazer algo [...] teria, sim, de esforçar-se para esclarecer, até onde é possível, seu propósito e, depois disso, calcular tudo e começar a trabalhar com espírito inabalável e pleno de confiança. Com tal coragem e confiança, a ação proposta terá êxito com toda probabilidade" ${ }^{2}$. É nesses termos que Fichte escreve ao comentar o capítulo XXV do Príncipe, para descrever o "estilo" do próprio príncipe de Maquiavel, que não tem de ser passivo frente à fortuna, mas tentar dominá-la, pelo menos de modo limitado. Dono de si mesmo é, neste sentido, quem, não confiando no favor da sorte, sabe controlar a si mesmo e ao mundo que lhe é exterior, através de um cálculo cuidadoso e apropriado, que nasce de uma elaboração individual de uma situação determinada.

esonnenheit, que é ligada a esta dominação de si mesmo, não coincide com uma autoconsciência imediata nem com um alcance de uma entidade transcendente. Tratase bem mais de um Verstand, isto é, de uma construção intelectual que não produz o seu objeto, mas define suas pretensões a partir da consciência de seus limites. No ensaio sobre Maquiavel, Fichte a entende como uma capacidade de dispor numa certa maneira "o coração em relação a certa situação imprevisível" e desvantajosa, reconduzindo-a à própria vantagem. No mesmo sentido, o homem cuidadoso não é quem tem confiança em Deus, mas quem age "como se não existisse Deus que pode ajudá-lo [...] como se tivesse de fazer tudo sozinho, como se Deus já o tivesse ajudado, como se Deus já o tivesse ajudado, dando [para quem age. N.d.E] ele mesmo" ${ }^{53}$. 
26 Na interpretação fichteana do Príncipe de Maquiavel, a estilização da existência baseada nestes pressupostos parece ligada, além disso, à aquisição de certa capacidade formativa que o indivíduo tem de exercitar sobre a matéria fornecida por sua própria vida, que, inicialmente, aparece como agregado contingente de elementos provenientes da experiência exterior ou da vida interior. O primeiro nível de desenvolvimento da capacidade é o da abertura de possibilidade formativa. Em primeiro lugar, o potencial oferecido pela vida tem de ser criado, configurado numa forma ou num modelo, através da elaboração intelectual e da projeção imaginativa ${ }^{54}$. Em segundo lugar, a capacidade formativa desenvolve-se num âmbito técnico em relação à realização das próprias possibilidades. As possibilidades têm de ser traduzidas em ação, sendo preciso possuir sabedoria sobre as modalidades nas quais o material oferecido pela vida pode ser plasmado. Apenas a execução da capacidade pode fornecer uma prova da sua existência real ${ }^{55}$. Desta maneira, a elaboração intelectual traduz-se em uma "autêntica força fundamental que plasma o mundo (bildend)" ${ }^{56}$, como Fichte afirma na Staatslehre. Enfim, a capacidade tem de ser ativa num sentido organizado e estratégico, realizando as possibilidades de maneira resoluta e sábia, à luz de uma visão aprofundada das estruturas, da reflexividade cultivada e de uma confiança com os aspectos de certo âmbito objetal ${ }^{57}$. Estilo e apropriação de si mesmo significam, neste sentido, capacidade de formar e de plasmar a si mesmo, sob o pressuposto de que "nada é impossível para uma vontade inabalável” ${ }^{\prime 2}$.

\section{Doutrina da ciência e arte de viver}

Com relação ao desenvolvimento da ideia da arte de viver, a doutrina da ciência se apresenta como modelo de pensamento que não se limita a levar à consciência os princípios gerais da ação, mas determina o momento particular e a maneira para fazêlo em função de circunstâncias presentes e atuais. Além disso, neste contexto, os conceitos-chave da doutrina da ciência (relação entre sensibilidade e razão, Besonnenheit, atenção, aplicação) perdem o significado abstrato ou de princípio, para adquirir significado em relação ao esclarecimento das condições de um comportamento (ou de uma conduta) individual. Trata-se de aspectos que os instrumentos fornecidos pelas reflexões de Foucault e Schmid acerca da estética da existência permitem trazer à luz e permitem ver em Fichte mais do que um autor de um pensamento abstrato e moralista, consequência da definição da filosofia como ciência rigorosa. Poder-se-ia tratar de outra maneira de atualizar o pensamento de Fichte? Acredito que um pensador fecundo e profundo como Fichte não precisa de atualizações. Com certeza, porém, a compreensão da doutrina da ciência precisa de perspectivas que permitam relevar esta profundidade e fecundidade e ligar de uma maneira mais explicita o rigor filosófico e a complexa linguagem fichteanos às questões que caracterizam o debate filosófico contemporâneo. Aproximar Fichte ao pensamento de Foucault e de Schmid em relação à arte de viver poderia representar um passo nesta direção, mas sob duas condições.

Primeira condição: uma revisão do esquema historiográfico geral através do qual Schmid e Foucault se relacionam com a filosofia moderna. Seja em Foucault, seja em Schmid, de fato, não há relação direta com o pensamento fichteano ou com a ideia global de doutrina da ciência. Para ambos, Fichte permaneceria inscrito em uma "época moderna", descrita como a época que perde o contato com os elementos concretos da 
existência, obcecada pelo "o pensamento de uma vida vera" a ser realizada por meio da "posse de bens" 59 . Uma possibilidade para revisar esse esquema foi apresentada pelo próprio Foucault, que considerou possível (ou até mesmo necessária) uma "retomada, pelo menos parcial, da história do pensamento do século XIX", já que pelo menos parte dela "poderia ser lida como tentativa, ou uma série de difíceis tentativas, de reconstituir uma ética do si" ${ }^{\circ}$. Ao longo da sua argumentação, Foucault menciona Stirner, Schopenhauer e Nietzsche. A compreensão da ideia global da doutrina da ciência em relação ao problema da arte de viver mostra como a de Fichte poderia ser incluída nesta série de tentativas, pois, em suas implicações fundamentais, a doutrina da ciência envolve, quer na forma de pressupostos quer na forma de implicações e aplicações, o desenvolvimento de uma técnica da existência, uma construção de uma ética concreta ${ }^{61}$ e uma reflexão sobre o sentido da existência como orientada para um valor, não definido a priori e sim construído pela cooperação entre agir individual e instância ética geral ${ }^{62}$.

Segunda condição: a concepção fichteana da lei moral como fato da razão não pode ser esquecida. Justamente em ocasião da discussão da possibilidade de reabilitar uma parte da filosofia do século XIX, Foucault escreve que a série de tentativas que foram empreendidas para reconstruir uma ética de si constitui uma situação "muito mais complicada, ambígua e contraditória" ${ }^{3}$. De fato, em Fichte a lei moral representa algo que não pode ser construído pela ação individual, a qual, na verdade, tem de submeterse ao comando da lei moral ordenadora. Esta perspectiva anularia a ideia, tipicamente foucaultiana, de uma ética do si que se constrói ao longo da história por camadas e desvios discursivos imprevisíveis. Entretanto a própria formação fichteana de uma ascética mostra como, ao passo que a lei moral poderia ser entendida a priori como algo não passível de ser construído pela ação individual, a ação concreta orientada pela lei moral tem de ter comprometimento com a dimensão sensível do próprio indivíduo. A ação ética individual, portanto, não pode ser entendida como simples submissão a algum comando moral, mas sim como re-construção estratégica do valor expresso na lei moral em função do contexto específico definido pelas inclinações individuais. Esta re-construção estratégica não anula o caráter categórico do comando. Porém o configura em formas e representações a cada vez diferentes. A filosofia aplicada de Fichte, e em especial a parte chamada de ascética, permite de fato desenvolver o conjunto de técnicas e de estratégias para construir essas representações. Nesta altura, que é a da filosofia aplicada e não a da filosofia primeira, a incostruibilidade do princípio ético não cria dificuldades, já que a questão não é a dos fundamentos de uma ética do si, e sim a das estruturas em que ela se articula.

Estas duas condições - revisão do esquema historiográfico foucaultiano/schmidiano e compreensão da relação entre o caractere categórico do princípio ético e aplicações sensíveis - poderiam fazer com que a ideia da arte de viver ou de estética da existência, mais do que se afastar das abstratas alturas da especulação fichteana, tornem-se instrumento fundamental para compreender a vitalidade do pensamento fichteano, ainda hoje. 


\section{BIBLIOGRAFIA}

\section{Bibliografia}

Cecchinato, G., 2009. Fichte und das Problem einer Aesthetik. Wuerzburg: Ergon.

Cohen, H., 1997. Deutschtum und Judentum. Mit grundlegenden Betrachtungen über Staat und Internationalismus. Em: Werke Bd. 16,. Hildesheim: Olms, pp. 472-475.

De Pascale, C., 1995. Etica e diritto. La filosofia pratica di Fichte e le sue ascendenze kantiane,. Bologna: il Mulino.

Derrida, J., 2001. Interpretazioni in guerra. Kant, l'ebreo, il tedesco. Naopli: Cronopio.

Domański, J., 1996. La philosophie, théorie ou manière de vivre? Les controverses de l'Antiquité à la Renaissance. Fribourg-Paris: Éditions universitaire.

Fabbianelli, F., 1998. Impulsi e libertà. Genova: Pantograf.

Ferraguto, F., 2010. Filosofare prima della filosofia. Hildesheim: Olms.

Ferraguto, F., 2012. Decisione e dedizione. Archivio di Filosofia, pp. 217-225.

Fonnesu, L., 2010. Per una morale concreta. Studi sulla filosofia classica tedesca. Bologna: Il Mulino.

Foucault, M., 1977. Preface. Em: G. Deleuze \& F. Guattari, eds. Anti Oedipus. Capitalism and Schizophrenia. New York: Viking, pp. XI-XIV.

Foucault, M., 2010. La cura di sé. Milano: Feltrinelli .

Foucault, M., 2011a. L'uso dei piaceri. Milano: Feltrinelli .

Foucault, M., 2011b. Ermeneutica del soggetto. Milano: Feltrinelli .

Foucault, M., 2013. , La volontà di sapere. Milano: Feltrinelli .

Hadot, I., 1969. Seneca und die griechisch-römische Tradition der Seelenleitung. Berlin: de Gruyter.

Hadot, P, 2010. Che cos'è la filosofia antica?. Torino: Einaudi.

Ivaldo, M., 1997. Politik, Geschichte und Religion in der Staatslehre von 1813. Fichte-Studien, Volume 11, pp. 209-227.

Kamalah, W., 1972. Philosophische Anthropologie. Sprachkritische Grundlegung und Ethik. Zurich: Bibliographisches Institut.

Kowalewski, A., 1965. Die philosophischen Hauptvorlesungen Immanuel Kants. Hildesheim ed. s.l.:Olms.

Krämer, H., 1976. "Prolegomena zu einer Kategorienlehre des richtigen Lebens". Philosophisches Jahrbuch.

Krämer, H., 1988. Pläydoyer für eine Philosophie der Lebenskunst”. Information Philosophie.

Krämer, H., 1992. Integrative Ethik. Frankfurt: Suhrkamp.

Lask, E., 1903. Fichte's Idealismus und die Geschichte. Tubingen-Leipzig: Mohr \& Siebek.

Lauth, R., 1999. Il sistema di Fichte nelle sue tarde lezioni berlinesi. Em: G. Rametta, ed. Dottrina della scienza. Esposizione del 1811. Milano: Guerini, pp. 11-52.. 
Pareyson, L., 1964. Die Walh der Philosophie nach Fichte. Em: F. Widemann, ed. Epimeleia. Die Sorge der Philosophie um den Menschen. München: Pustet, pp. 30-60.

Rabbow, P., 1954. Seelenführung. Methodik der Exerzitien in der Antike. Muenchen: Kösel.

Radrizzani, I., 1996. La Doctrine de la Science et l'engagement historique. Revue de Métaphysique et de Morale, pp. 23-47.

Rametta, G., 2008. La theorie fichtéenne de la conscience dans une perspéctive biopolitique. Em: J. C. Goddard \& J. Rivera de Rosales, eds. Fichte et la politique. Monza: Polimetrica, pp. 431-442.

Rendtorff, T., 1990-1991. Ethik. Grundelemente, methodologie und Konkretionen einer ethischen Theologie. Tuebingen: Mohr.

Schmid, W., 1991. Auf der Suche nach einer neuen Lebenskunst. Frankfurt: Suhrkamp.

Schmid, W., 2000. , Die philosophie im Garten der Lueste. Frankfurt: Suhrkamp.

Schmid, W., 2012. L'amicizia per se stessi. Roma: Fazi .

Schmid, W., 2014. Filosofia dell'arte di vivere. Roma: Fazi .

Schopenhauer, A., 2005. 0 mundo como vontade e representação. São Paulo: UNESP.

Traub, H. \& Össtereich, P. L., 2006. Der ganze Fichte. Die populäre, wissenschaftliche und metaphilosophische Erschliessung der Welt. Stuttgart : Konigshausen.

Voelke, A., 1993. La philosophie come thérapie de l'âme. Études de philosophie hellénistique. FreiburgParis: Cerf.

\section{NOTAS}

1. Para uma apresentação da concepção geral da doutrina da ciência veja Lauth 1999. Uma reflexão extensa acerca da função sistemática da filosofia aplicada em Fichte se encontra em Ivaldo 1997.

2. Fichte apresenta uma tratação sistematica da filosofia aplicada também em 1805, nos Principien der Gottes, Sitten und Rechtslehre, onde define o percurso da aplicação da filosofia como "pesquisa em torno de um material já dado, o qual ao longo da própria pesquisa não fica dado, e sim derivante do saber" (GA, II, 7, p. 380). Entretanto, e como veremos mais para a frente, nos Principien Fichte se foca mais sobre a dedução dos "princípios essendi" (GA II, 7, p. 378) das disciplinas filosóficas aplicadas, enquanto na Asketik trata dos elementos antropológicos envolvidos na própria aplicação da filosofia.

3. GA II, 5, p. 60.

4. A conexão entre desenvolvimento da doutrina da ciencia e reforma geral das condições sociais e existenciais da humanidade se encontra de uma maneira explicita nas Einleitungsvorlesungen in die Wissenschaftslehre 1813, SW, IX, em especial p. 3-4, na segunda Transzedentale Logik del 1812 (ed Meiner, p. 253 e p. 260) e chamada de Staatslehre (SW, IV, p. 390). A questão da função politica e historica do „savio“ em Fichte é discutida de maneria precisa por Radrizzani 1996: 36 e 43-44. Uma interpretação muito pertinente da conexão fichteana entre formação da filosofia como ciencia rigorosa e retorno da filosofia na vida na forma de renovação social e politica da humanidade é apresentada já por Hermann Cohen no ensaio de 1915 Deutschtum umd Judentum, agora em Cohen 1997: 472-475. Elementos teoricos interessantes para aprofundar este problema encontram-se em Derrida 2001: 83.

5. GA, II, 5, p. 60.

6. Einleitungsvorlesungen 1813, SW, IX, 20. 
7. Esta concepção fica evidente nos Tatsachen des Bewusstseins, cf. em especial GA II, 11, p. 88.

8. Entre as varias expressões da Fichte-Forschung que levam á tona este aspeito vale a pena lembar Össtereich - Traub 2006.

9. Não se pode afirmar que Fichte produziu uma ética estetizante, ao passo que o ponto de chegada da arte de viver é a formação de uma estética da existência (Foucault 2010: 97). Entretanto, uma possível conciliação teórica entre arte de viver em um sentido geral e estética da existência pode já ser encontrada na reflexão sobre o significado transcendental da arte, assim como foi concebida por Fichte, ou seja, como instrumento que permite mediar entre o nível puro dos princípios morais e o individual da concretização deles. Para esclarecimentos sobre a concepção fichteana da arte cf. Cecchinato 2009.

10. Veja a respeito Foucault 2011: 76.

11. In particolare, Filosofia dell'arte di vivere, trad. it. a cura di F. Ferraguto, Roma, Fazi, 2014.

12. Esta interpretação da filosofia de Fichte é desenlvida já por Lask 1903.

13. Além da pesquisa foucaultiana (Foucault 2013, 2011a, 2010, 2011b), vale a pena citar uns exemplos desta rehabilitação da filosofia da arte de viver no debate contemporaneo. Sobre a arte de viver na filosofia antiga cf. Rabbow1954; Hadot 1969.; Hadot 2008; Voelke 1993; Hadot 2010; Domański 1996. Sobre os princípios teóricos da filosofia como arte de viver no sentido foucaultiano cf. Schmid 1991; Schmid 2014. Sobre as implicações eticas da concepção da filosofia como arte de viver veja Kamalah, 1972 (ivi, p. 167); Krämer, 1976; Rendtorff (em espcial, vol. I, p. 9 sg. e p. 130 sg.); Krämer 1992, que põe a questão da coerência entre tica do dever e ética do esforço na construção da conduta individual; Krämer 1988. A conexão entre a perspectiva foucaultiana e a concepção grega de arte de viver foi estudada por Schmid 2000.

14. Foucault 2010: 99.

15. Foucault 2010: 48.

16. Foucault 1977: XI-XIV.

17. Foucault 2010: 33.

18. Schmid 2014: 59-60.

19. Nesta direção se orienta Schmid 2012.

20. GA II, 5, p. 67.

21. Veja Kant, Anthropologie in pragmatischer Hinsicht, AK, VII, p. 119. Sobre a função da arte de viver no programa filosofico kantiano cf. Kowalewski 1965: 62.

22. Schmid 2014: 33.

23. Trata-se de questões desenvolvidas nos $\S 25-27$ da Antropologia.

24. Trata-se de uma série de anotações relativamente fragmentarias publicadas pela primeira vez no tomo III dos Nachgelassenen Werke editorado por I.E. Fichte, de que não há versão autografa redigida pelo próprio Fichte. Conforme os dados filológicos apresentados em GA II, 5, 57-58 a Asketik deve corresponder a uma Vorlesung ministrada por Fichte no semestre invernal de 1798-99 como apêndice à apresentação da doutrina moral de 1798.

25. Sobre as diferencias e as relações entre antropologia kantiana e fichteana cf. Fabbianelli 1998; Fonnesu 2010; De Pascale 1995.
26. GA I, $5,171 \mathrm{sg}$
27. GA II, 5, 63.
28. GA I, $1,55$.
29. GA II, 5, 67.
30. GA II, 5, 67.
31. GA II, 5, p. 69. 
32. GA II, 5, p. 69.

33. Este conceito tem que ser distinguido de uma maneira radical do Schopenhaueriano, conforme a ascética seria uma "autopunição ou autoflagelo" (Schopenhauer 2005: 484).

34. Una interpretazione della relazione stabilita da Fichte tra coscienza e vita in questo senso, come tensione tra un orizzonte immanente e impersonale e atti di posizione riflessiva di sé è stata data da Rametta 2008.

35. GA II, 5, 62-63.

36. GA II, 5, 64 .

37. GA I, $1,87$.

38. GA, II, 5, 66 .

39. Ibid.

40. GA, II, 5, 67 .

41. II, $5,68$.

42. Para uma análise desta passagem cf. Ferraguto 2012.

43. II, $5,67$.

44. II, 5,71 .

45. Foucault 2011a: 110.

46. Veja a respeito desta concepção de estilo Foucault 2010: 99; Schmid 2014: 132 sg.

47. Foucault 2010: 67.

48. Foucault 2011b: 58-61. Uma análise desta passagem há em Schmid 2000: 80-130, que pretende aprofundar os resultados foucaultianos.

49. Neste sentido poder-se-ia ler a questão da escolha desenvolvida na Erste Einleitung in die Wissenschaftslehre (1797). Para uma interpretação desta questão, que retome a ideia grega de epimeleia introduzida também por Foucault veja Pareyson1964.

50. Veja a respeito Ferraguto 2010.

51. GA II, 13, 41-42.

52. GA I, 9, 266.

53. GA I, 9, 266.

54. Machiavelli, GA I, 9, 267: "Es thut im Verfolge einer Unternehmung sich ein Umstand hervor, der an sich weder nothwendig war, noch durch irgend einen menschlichen Verstand vorherzusehen. Der verständige Mann durchschaut auf der Stelle, wie derselbe zu gebrauchen sei für seinen Zweck, und gebraucht ihn also; er, der vielleicht, wenn statt des eingetretnen gerade sein Gegentheil sich ereignet hätte, auch dieses eben so zweckmäßig gefunden haben würdetrad".

55. GA, I, 9, 267-268.

56. SW, IV, 389..

57. GA, I, 9 268: "Die Menge, welche zwischen dem Froste, und der Eroberung kein Mittelglied weiter erblickt, staunt sein Glück an, und es ist sein Vortheil, sie dabei zu lassen, weil dies in das Gebiet des Wunderbaren fällt, und den Mann zum besondern Lieblinge der Gottheit erhebt, dagegen die nackte Wahrheit, daß sein Glück auf seinem Verstande beruht habe, viel zu gemein, und zu natürlich ist".

58. GA I, 9, 269.

59. Schmid 2014: 37.

60. Foucault 2011b: 221.

61. A respeito veja Ivaldo 1992.

62. Trata-se de uma ideia desenvolvida por Emil Lask em Lask 1903:128, 165, 28-44, 73-76 com referência a noção de Wertindividualität, individualidade válida ou individualidade de valor. Conforme Lask, Fichte diferencia a esfera do valer daquela do ser, pensando o "fazer-se" do valor em um ente particular. O individual é considerado como parte integrante do processo de constituição do valor, não por força de seu ser, mas em razão de uma visão da sua potencialidade 
de realizar uma exigência prática. Lask atribui, de fato, à reflexão fichteana sobre a filosofia aplicada (e em especial ao conceito de revelação, que como vimos apresenta muitas analogias com o de ascética) um papel crucial, pois é graças à ideia de revelação que se pode esclarecer como um fenômeno histórico-individual é capaz de exibir um "novo" não antecipável segundo conceitos.

63. Foucault 2011b: 221.

\section{RESUMOS}

The paper aims to a discussion of the possibility of reading Fichte's Wissenschaftslehre such as a form of "art of living". Firstly, it will be presented and discussed Fichte's conception of ascetic, such as it was treated in the Aschetik als Anhang zur Moral of 1798 (§§ 2-3) and Fichte's interpretation of the Besonnenheit in the commentary to the chapter XXV of Machiavelli's Prince, that constitute a central element of 1807's essay Machiavelli als Schriftsteller (§ 4). Finally, it will be critically valued the conditions of possibility for approximating Fichte's concept of ascetic to the contemporary reflection upon the art of living developed from Michel Foucault and Wilhelm Schmid (§§ 4-5).

\section{ÍNDICE}

Keywords: Fichte, Foucault, Art of Living, Transcendental Philosophy, Ascetic

\section{AUTOR \\ FEDERICO FERRAGUTO}

PUCPR, Curitiba 